\title{
The role of desmosomes in carcinogenesis
}

\author{
Guangxin Zhou' \\ Linlin Yang ${ }^{2}$ \\ Ashley Gray ${ }^{3}$ \\ Amit Kumar Srivastava ${ }^{4}$ \\ Cuiping $\mathrm{Li}^{5}$ \\ Gongwen Zhang ${ }^{6}$ \\ Tiantian Cui ${ }^{2}$
}

'Department of Oncology, Central Hospital of Binzhou, Binzhou Medical College, Binzhou, People's Republic of China; ${ }^{2}$ Department of Radiation Oncology, Arthur G James Hospital/ Ohio State Comprehensive Cancer Center, ${ }^{3}$ The Ohio State University, ${ }^{4}$ Division of Radiobiology, Department of Radiology, The Ohio State University Wexner Medical Center, Columbus, OH, USA; ${ }^{5}$ Department of Respiratory Medicine, ${ }^{6}$ Department of Cardiac Surgery, Central Hospital of Binzhou, Binzhou Medical College, Binzhou, People's Republic of China

Correspondence: Tiantian Cui Department of Radiation Oncology, Arthur G James Hospital/Ohio State Comprehensive Cancer Center, 35I Wisemen Hall, 4IOW I2th Ave, Columbus, $\mathrm{OH} 43210$, USA

$\mathrm{Tel}+\mathrm{I} 6143124765$

Email tiantian.cui@osumc.edu
This article was published in the following Dove Press journal:

OncoTargets and Therapy

14 August 2017

Number of times this article has been viewed
Abstract: Desmosomes, which are intercellular adhesive complexes, are essential for the maintenance of epithelial homeostasis. They are located at the cell membrane, where they act as anchors for intermediate filaments. Downregulation of desmosome proteins in various cancers promotes tumor progression. However, the role of desmosomes in carcinogenesis is still being elucidated. Recent studies revealed that desmosome family members play a crucial role in tumor suppression or tumor promotion. This review focuses on studies that provide insights into the role of desmosomes in carcinogenesis and address their molecular functions.

Keywords: desmosome, desmosomal cadherin, $\beta$-catenin, plakoglobin, plakophilins, desmoplakin

\section{Introduction}

Desmosomes are intercellular junctions that, in association with intermediate filaments, mechanically link cells and stabilize tissue architecture. ${ }^{1}$ Desmosome structure was first observed in 1864 by Bizzozero, an Italian pathologist; its structure has since been analyzed by techniques such as electron microscopy (EM) to reveal a complex structure and organization. The desmosomal components comprise three main protein families: transmembrane cadherin family (desmogleins [DSGs] and desmocollins [DSCs]), armadillo (ARM) protein family (plakoglobin [PKG], plakophilins [PKPs], and $\beta$-catenin), and plakin protein family (desmoplakin [DSP]). Genes encoding desmosomal constituents were found mutated, which can have effects on tissue integrity; but they are not only simple static adhesive structures, increased evidences show that desmosomes also act as tumor suppressors or oncogenes in various cancers, regulating cell proliferation, differentiation, migration, apoptosis, and treatment sensitivity. ${ }^{2}$ The following sections of this review describe the structure of the desmosome family members and functional characteristics of the major desmosomal proteins.

\section{Desmosomal structure}

\section{Desmosomal cadherin family}

DSGs (Dsg1-4) and DSCs (Dsc1-3) are desmosomal cadherin family members found in humans. DSGs and DSCs are required for strong cell-cell adhesion ${ }^{3}$ via their interaction with each other across the intercellular space (Figure 1), in a homophilic and/or heterophilic manner; the difference between the two types of interactions remains unclear. These desmosomal cadherins show complex developmental and differentiation patterns of expression. ${ }^{1,4}$ Dsg1/3 and Dsc1/3 are present in stratified epithelia, and Dsg4 is found in stratified epithelia and hair..$^{5-7}$ Dsg2 and Dsc2 are the primary isoforms in simple epithelia and are present at low levels in the basal layer of stratified epithelia. ${ }^{6}$ All three DSC1-3 gene products undergo alternative splicing, resulting in the generation of the Dsc "a" form and a shorter Dsc " $b$ " form of 


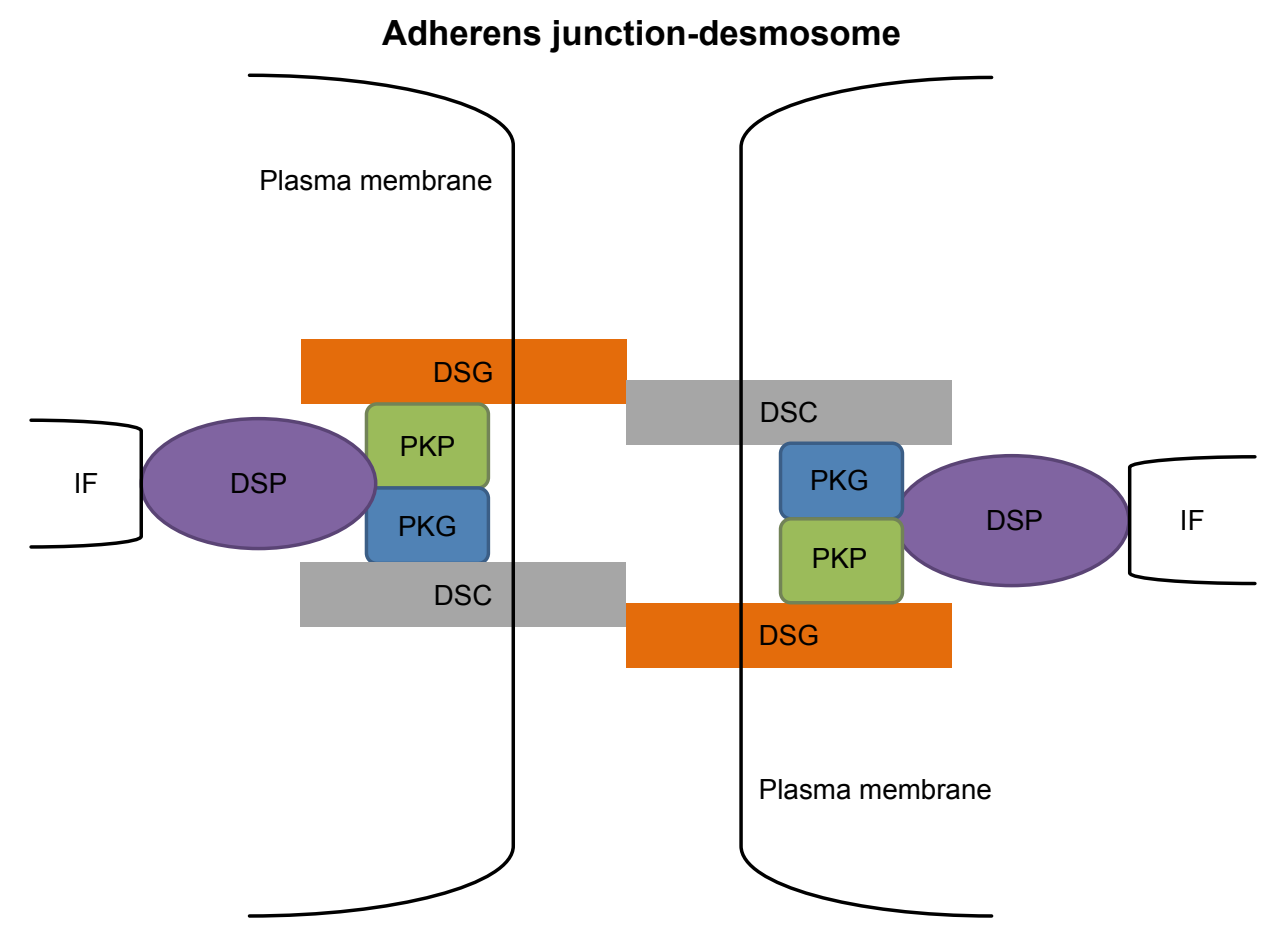

Figure I A model for the structure of desmosomes.

Abbreviations: DSC, desmocollin; DSG, desmoglein; DSP, desmoplakin; IF, intermediate filaments; PKG, plakoglobin; PKP, plakophilin.

the proteins, which differ in the length of their respective carboxy-terminal domains. ${ }^{89}$ The DSC extracellular (EC) domains can be divided into a number of subdomains, including four cadherin-like EC domains and an extracellular anchor (EA) domain. DSG EC domains are organized in a similar fashion. Within the cell, both DSC "a" and "b" proteins possess an intracellular anchor (IA) domain, but only "a" form proteins have an intracellular cadherin-like sequence (ICS) domain. DSG cytoplasmic tails also have IA and ICS domains. DSC and DSG ICS domains provide binding sites for other desmosomal constituents. ${ }^{10}$

\section{ARM family}

ARM family members are mainly $\beta$-catenin, PKG (or $\gamma$-catenin), and PKPs (PKP1-3). ${ }^{11}$ They are characterized by the presence of a central domain, containing repeating units of a 42 amino acid sequence homology domain, ${ }^{12}$ and they mediate the cytoplasmic associations with the cadherins. $\beta$-Catenin consists of several very characteristic repeats, each $\sim 40$ amino acids long. All these $\beta$-catenin elements fold together into a single, rigid protein domain with an elongated shape, called an ARM domain. PKG, which contains 12 arm repeats, exhibits dual localization in desmosomes and adherens junctions. In addition, $\beta$-catenin contributes to desmosomes only in PKG-negative organisms. PKPs contain 9 arm repeats with a flexible insert between repeats 5 and 6 that introduces a major bend in the overall structure. ${ }^{13}$ There are two isoforms of PKPs 1 and 2, a shorter "a" form and a longer " $b$ " form, generated by alternative splicing. PKP1a and $1 \mathrm{~b}$ differ by the insertion of 21 amino acids between arm repeats 3 and 4, whereas PKP2a and 2b differ by the insertion of 44 amino acids between repeats 2 and $3 .^{14,15}$

\section{Plakin family}

There are several plakin proteins, including DSP, plectin, envoplakin, and periplakin. DSP, which is the most abundant component of the plakin family, interacts with other desmosomal family members, such as PKG, PKPs, and intermediate filaments, providing the link in the chain from the plasma membrane to the cytoskeleton. ${ }^{16}$ The DSP gene is located on chromosome 6p24.3, containing 24 exons and spanning $\sim 45 \mathrm{kDa}$ of genomic DNA. ${ }^{17}$ There are two predominant isoforms; the first, known as "DPI", has molecular weight $332 \mathrm{kDa}$ (2,871 amino acids) and the second, known as "DPII", has molecular weight $260 \mathrm{kDa}(2,272$ amino acids). These isoforms are identical except for the shorter rod domain in DPII. DPI is the predominant isoform expressed in cardiac muscle. ${ }^{18}$ Although DPI and DPII are functionally redundant, loss of the C-terminal tail domain from DPI/DPII has devastating consequences on skin integrity and results in early neonatal death in lethal acantholytic epidermolysis bullosa. ${ }^{19}$ 


\section{The role of desmosome in cancer}

During the past 15-20 years, studies revealed the role of desmosome in human diseases, especially in heart and skin diseases. Although the role of desmosome proteins in cancer development and progression is not clear, some recent progress has been made. ${ }^{20}$ Recently, a body of evidence shows that they may influence epithelial cell invasion and metastasis since an important function of desmosomes related to cancer is their ability to inhibit cell motility. ${ }^{21}$

\section{Desmosomal cadherins and cancer}

Recently, studies have shown that desmosomal proteins have both tumor-promoting and tumor-suppressive functions in different types of cancers. ${ }^{22}$ For example, DSG2 is found to be overexpressed in skin cancer, ${ }^{23}$ and overexpression of DSG2 promotes lung cancer cell growth through regulation of $\mathrm{p} 27$ and CDK2. ${ }^{24}$ DSG3 was upregulated in head and neck cancer and lung cancer. ${ }^{25,26}$ Brown et $\mathrm{al}^{27}$ showed that DSG3 promotes cancer cell migration and invasion by regulating AP-1 and PKC in head and neck cancer. By contrast, loss of DSC2 contributes to the growth of colorectal cancer cells by regulating Akt/ $\beta$-catenin signaling. ${ }^{28} \mathrm{DSC} 3$ ablation increased the incidence of Ras-induced skin tumors in mice; ${ }^{29}$ furthermore, it is found to be downregulated in breast, lung, and colorectal cancers due to promoter hypermethylation. ${ }^{10,30,31} \mathrm{We}$ found that ectopic expression of DSC3 by introducing a DSC3 expression vector into lung cancer cells successfully suppressed lung cancer cell growth and motility through inactivation of the EGFR/ERK signaling pathway. ${ }^{30}$ Desmosomal cadherin proteins have also been considered as prognostic markers in various cancer types. For example, decreased DSG3 expression was associated with poor prognosis in lung cancer. ${ }^{26}$ Our studies showed that DSC1 may be a marker for tumor differentiation, DSC3 has a potential diagnostic value in sub-classification of non-small-cell lung cancer (NSCLC) into squamous cell carcinoma (SCC) and adenocarcinoma (ADC), and furthermore, DSC1 and DSC3 may be prognostic markers for lung cancer. ${ }^{32}$

\section{ARM proteins and signaling pathway}

ARM proteins also mediate important signal transduction pathways in human cancer. $\beta$-Catenin, which is widely expressed in many tissues, is involved in regulation and coordination of cell-cell adhesion and gene transcription. Meanwhile, it acts as an intracellular signal transducer in the Wnt signaling pathway. The Wnt signaling pathway plays an essential role in embryonic development and stemness and has also been described in carcinogenesis. ${ }^{33}$ When the Wnt signaling pathway is activated by the binding of Wnt ligands to the Frizzled receptors and the low-density lipoprotein coreceptors, the degradation complex is inactivated, resulting in the stabilization of $\beta$-catenin. This leads to the translocation of $\beta$-catenin into the nucleus where it associates with the lymphoid enhancer factor/T-cell factor (LEF/TCF) family of transcription factors to activate many downstream target genes. ${ }^{34}$ More details of the $\mathrm{Wnt} / \beta$-catenin signaling pathway can be found elsewhere. ${ }^{33}$

$\mathrm{PKG}$, which is closely related to $\beta$-catenin, is another important member of ARM family. It interacts with similar molecules, such as $\beta$-catenin. Miravet et $\mathrm{al}^{35}$ found that PKG could reduce transcription of Wnt target genes through binding to adjacent sites on Tcf-4 with $\beta$-catenin and inhibiting binding of Tcf-4 to DNA. Thus, PKG is a negative regulator of $\mathrm{Wnt} / \beta$-catenin signaling and acts as a tumor/metastasis suppressor in various cancers. For example, in ovarian cancer, exogenous expression of PKG or knockdown of $\mathrm{N}$-cadherin is more effective than expression of E-cadherin in inhibiting the growth, migratory, and invasive properties of ES-2 cells. ${ }^{36}$ PKG-mediated HAI-1 regulation offers a promising novel strategy to inhibit the c-MET signaling pathway in lung cancer. ${ }^{37}$ Silencing PKG in esophageal cancer cells causes defects in cell-cell adhesion and a concomitant increase in cell migration. ${ }^{38}$

PKPs, which have been characterized as desmosomal plaque proteins, stabilize desmosomal cadherins at the plasma membrane and interact with the cytoskeletal linker protein DSP. They are predominantly expressed in epithelial cells with distinct expression patterns. PKP 1 is found in suprabasal layers of epithelia, while PKPs 2 and 3 localize to desmosomes from simple epithelia. ${ }^{39}$ Like $\beta$-catenin, PKPs have diverse non-desmosomal functions. Loss of PKPs 1-3 is found in some tumors. ${ }^{40-42}$ Reduced PKP 3 expression is correlated with desmosome instability, increased cell migration, and poor prognoses for patients. Mechanistically, it is transcriptionally repressed by E-cadherin repressor ZEB1 in tumor cells, which suggests a common regulation for adherens junctions and desmosomes during tumor progression. ${ }^{43}$ Surprisingly, in other tumors, PKP 1 or 3 is overexpressed, such as head and neck tumors, ${ }^{44}$ lung cancer, ${ }^{26}$ and Ewing sarcoma. ${ }^{45}$

\section{DSP and Wnt signaling pathway}

DSP proteins are widely expressed in numerous tissues. ${ }^{46,47}$ Loss of expression of DSP promotes increased local tumor invasion in a mouse model of pancreatic neuroendocrine carcinogenesis. ${ }^{48}$ Interestingly, in keratinocytes, decreased 
expression of DSP could increase cell proliferation associated with elevated phospho-ERK1/2 and phospho-Akt levels. ${ }^{49}$ In our studies, we found that DNA methylation contributes to the downregulation of DSP in lung cancer. Additionally, ectopic expression of DSP enhanced expression of PKG ( $\gamma$-catenin), which is a component modulating the Wnt signaling pathway, resulting in decreased TCF/LEF-dependent transcriptional activity and reduced expression of the Wnt/ $\beta$ catenin target genes, Axin2 and matrix metalloproteinase MMP14. The epigenetic regulation of DSP and its ability to increase the sensitivity to anticancer drug-induced apoptosis has potential implications for clinical application. ${ }^{50}$

\section{Conclusion}

Although a substantial amount of evidence is available to support the idea that desmosomes are involved in progression of cancer, unlike the role of desmosomes in adherens junctions, our understanding of the role of desmosomes and how they are involved in cancer and metastasis is still evolving. Additional studies are necessary to explore the complete function of desmosomes in human cancer. A better understanding of the regulatory mechanisms of the expression changes of desmosomes and their role as mediators of intracellular signal transduction will be important, especially for personalized therapeutic strategies. Progression on the mechanistic study will lead to a better understanding of the role of desmosomes in malignancy and have implications for cancer treatment.

\section{Disclosure}

The authors report no conflicts of interest in this work.

\section{References}

1. Holthofer B, Windoffer R, Troyanovsky S, Leube RE. Structure and function of desmosomes. Int Rev Cytol. 2007;264:65-163.

2. Dusek RL, Attardi LD. Desmosomes: new perpetrators in tumour suppression. Nat Rev Cancer. 2011;11(5):317-323.

3. Getsios S, Huen AC, Green KJ. Working out the strength and flexibility of desmosomes. Nat Rev Mol Cell Biol. 2004;5(4):271-281.

4. Kowalczyk AP, Green KJ. Structure, function, and regulation of desmosomes. Prog Mol Biol Transl Sci. 2013;116:95-118.

5. Brooke MA, Nitoiu D, Kelsell DP. Cell-cell connectivity: desmosomes and disease. J Pathol. 2012;226(2):158-171.

6. Garrod D, Chidgey M. Desmosome structure, composition and function. Biochim Biophys Acta. 2008;1778(3):572-587.

7. Johnson JL, Koetsier JL, Sirico A, et al. The desmosomal protein desmoglein 1 aids recovery of epidermal differentiation after acute UV light exposure. J Invest Dermatol. 2014;134(8):2154-2162.

8. Collins JE, Legan PK, Kenny TP, MacGarvie J, Holton JL, Garrod DR. Cloning and sequence analysis of desmosomal glycoproteins 2 and 3 (desmocollins): cadherin-like desmosomal adhesion molecules with heterogeneous cytoplasmic domains. J Cell Biol. 1991;113(2):381-391.

9. Parker AE, Wheeler GN, Arnemann J, et al. Desmosomal glycoproteins II and III. Cadherin-like junctional molecules generated by alternative splicing. J Biol Chem. 1991;266(16):10438-10445.
10. Cui T, Chen Y, Yang L, et al. DSC3 expression is regulated by $\mathrm{p} 53$, and methylation of DSC3 DNA is a prognostic marker in human colorectal cancer. Br J Cancer. 2011;104(6):1013-1019.

11. Hatzfeld M. The p120 family of cell adhesion molecules. Eur J Cell Biol. 2005;84(2-3):205-214.

12. Peifer M, McCrea PD, Green KJ, Wieschaus E, Gumbiner BM. The vertebrate adhesive junction proteins beta-catenin and plakoglobin and the Drosophila segment polarity gene armadillo form a multigene family with similar properties. J Cell Biol. 1992;118(3):681-691.

13. Choi HJ, Weis WI. Structure of the armadillo repeat domain of plakophilin 1. J Mol Biol. 2005;346(1):367-376.

14. Mertens C, Kuhn C, Franke WW. Plakophilins 2a and 2b: constitutive proteins of dual location in the karyoplasm and the desmosomal plaque. J Cell Biol. 1996;135(4):1009-1025.

15. Schmidt A, Langbein L, Rode M, Pratzel S, Zimbelmann R, Franke WW. Plakophilins $1 \mathrm{a}$ and $1 \mathrm{~b}$ : widespread nuclear proteins recruited in specific epithelial cells as desmosomal plaque components. Cell Tissue Res. 1997;290(3):481-499.

16. Smith EA, Fuchs E. Defining the interactions between intermediate filaments and desmosomes. J Cell Biol. 1998;141(5):1229-1241.

17. Green KJ, Parry DA, Steinert PM, et al. Structure of the human desmoplakins. Implications for function in the desmosomal plaque. $J$ Biol Chem. 1990;265(19):11406-11407.

18. Al-Jassar C, Bikker H, Overduin M, Chidgey M. Mechanistic basis of desmosome-targeted diseases. J Mol Biol. 2013;425(21):4006-4022.

19. McGrath JA, McMillan JR, Shemanko CS, et al. Mutations in the plakophilin 1 gene result in ectodermal dysplasia/skin fragility syndrome. Nat Genet. 1997;17(2):240-244.

20. Broussard JA, Getsios S, Green KJ. Desmosome regulation and signaling in disease. Cell Tissue Res. 2015;360(3):501-512.

21. Tselepis C, Chidgey M, North A, Garrod D. Desmosomal adhesion inhibits invasive behavior. Proc Natl Acad Sci U S A. 1998;95(14): 8064-8069.

22. Chidgey M, Dawson C. Desmosomes: a role in cancer? Br J Cancer. 2007;96(12):1783-1787.

23. Kurzen H, Munzing I, Hartschuh W. Expression of desmosomal proteins in squamous cell carcinomas of the skin. J Cutan Pathol. 2003; 30(10):621-630.

24. Cai F, Zhu Q, Miao Y, Shen S, Su X, Shi Y. Desmoglein-2 is overexpressed in non-small cell lung cancer tissues and its knockdown suppresses NSCLC growth by regulation of $\mathrm{p} 27$ and CDK2.J Cancer Res Clin Oncol. 2017;143(1):59-69.

25. Chen YJ, Chang JT, Lee L, et al. DSG3 is overexpressed in head neck cancer and is a potential molecular target for inhibition of oncogenesis. Oncogene. 2007;26(3):467-476.

26. Furukawa C, Daigo Y, Ishikawa N, et al. Plakophilin 3 oncogene as prognostic marker and therapeutic target for lung cancer. Cancer Res. 2005;65(16):7102-7110.

27. Brown L, Waseem A, Cruz IN, et al. Desmoglein 3 promotes cancer cell migration and invasion by regulating activator protein 1 and protein kinase C-dependent-Ezrin activation. Oncogene. 2014;33(18): 2363-2374.

28. Kolegraff K, Nava P, Helms MN, Parkos CA, Nusrat A. Loss of desmocollin-2 confers a tumorigenic phenotype to colonic epithelial cells through activation of Akt/beta-catenin signaling. Mol Biol Cell. 2011;22(8):1121-1134.

29. Chen J, O’Shea C, Fitzpatrick JE, Koster MI, Koch PJ. Loss of desmocollin 3 in skin tumor development and progression. Mol Carcinog. 2012;51(7):535-545.

30. Cui T, Chen Y, Yang L, et al. The p53 target gene desmocollin 3 acts as a novel tumor suppressor through inhibiting EGFR/ERK pathway in human lung cancer. Carcinogenesis. 2012;33(12):2326-2333.

31. Oshiro MM, Kim CJ, Wozniak RJ, et al. Epigenetic silencing of DSC3 is a common event in human breast cancer. Breast Cancer Res. 2005; 7(5):R669-R680.

32. Cui T, Chen Y, Yang L, et al. Diagnostic and prognostic impact of desmocollins in human lung cancer. J Clin Pathol. 2012;65(12):1100-1106. 
33. Li TW, Ting JH, Yokoyama NN, Bernstein A, van de Wetering M, Waterman ML. Wnt activation and alternative promoter repression of LEF1 in colon cancer. Mol Cell Biol. 2006;26(14):5284-5299.

34. MacDonald BT, Tamai K, He X. Wnt/beta-catenin signaling: components, mechanisms, and diseases. Dev Cell. 2009;17(1):9-26.

35. Miravet S, Piedra J, Miro F, Itarte E, Garcia de Herreros A, Dunach M The transcriptional factor Tcf-4 contains different binding sites for beta-catenin and plakoglobin. J Biol Chem. 2002;277(3):1884-1891.

36. Alaee M, Danesh G, Pasdar M. Plakoglobin reduces the in vitro growth, migration and invasion of ovarian cancer cells expressing $\mathrm{N}$-cadherin and mutant p53. PLoS One. 2016;11(5):e0154323.

37. Sechler M, Borowicz S, Van Scoyk M, et al. Novel role for gammacatenin in the regulation of cancer cell migration via the induction of hepatocyte growth factor activator inhibitor type 1 (HAI-1). J Biol Chem. 2015;290(25):15610-15620.

38. Fang WK, Liao LD, Li LY, et al. Down-regulated desmocollin-2 promotes cell aggressiveness through redistributing adherens junctions and activating beta-catenin signalling in oesophageal squamous cell carcinoma. J Pathol. 2013;231(2):257-270.

39. Bass-Zubek AE, Hobbs RP, Amargo EV, et al. Plakophilin 2: a critical scaffold for PKC alpha that regulates intercellular junction assembly. J Cell Biol. 2008;181(4):605-613.

40. Schmitt-Graeff A, Koeninger A, Olschewski M, et al. The Ki67+ proliferation index correlates with increased cellular retinol-binding protein-1 and the coordinated loss of plakophilin-1 and desmoplakin during progression of cervical squamous lesions. Histopathology. 2007;51(1):87-97.

41. Schwarz J, Ayim A, Schmidt A, et al. Differential expression of desmosomal plakophilins in various types of carcinomas: correlation with cell type and differentiation. Hum Pathol. 2006;37(5):613-622.
42. Sobolik-Delmaire T, Reddy R, Pashaj A, Roberts BJ, Wahl JK 3rd. Plakophilin-1 localizes to the nucleus and interacts with single-stranded DNA. J Invest Dermatol. 2010;130(11):2638-2646.

43. Aigner K, Descovich L, Mikula M, et al. The transcription factor ZEB1 (deltaEF1) represses Plakophilin 3 during human cancer progression. FEBS Lett. 2007;581(8):1617-1624.

44. Villaret DB, Wang T, Dillon D, et al. Identification of genes overexpressed in head and neck squamous cell carcinoma using a combination of complementary DNA subtraction and microarray analysis. Laryngoscope. 2000;110(3 pt 1):374-381.

45. Cheung IY, Feng Y, Danis K, et al. Novel markers of subclinical disease for Ewing family tumors from gene expression profiling. Clin Cancer Res. 2007;13(23):6978-6983.

46. Angst BD, Nilles LA, Green KJ. Desmoplakin II expression is not restricted to stratified epithelia. J Cell Sci. 1990;97(pt 2):247-257.

47. Delva E, Tucker DK, Kowalczyk AP. The desmosome. Cold Spring Harb Perspect Biol. 2009;1(2):a002543.

48. Chun MG, Hanahan D. Genetic deletion of the desmosomal component desmoplakin promotes tumor microinvasion in a mouse model of pancreatic neuroendocrine carcinogenesis. PLoS Genet. 2010; 6(9):e1001120.

49. Wan H, South AP, Hart IR. Increased keratinocyte proliferation initiated through downregulation of desmoplakin by RNA interference. Exp Cell Res. 2007;313(11):2336-2344.

50. Yang L, Chen Y, Cui T, et al. Desmoplakin acts as a tumor suppressor by inhibition of the Wnt/beta-catenin signaling pathway in human lung cancer. Carcinogenesis. 2012;33(10):1863-1870.
OncoTargets and Therapy

\section{Publish your work in this journal}

OncoTargets and Therapy is an international, peer-reviewed, open access journal focusing on the pathological basis of all cancers, potential targets for therapy and treatment protocols employed to improve the management of cancer patients. The journal also focuses on the impact of management programs and new therapeutic agents and protocols on

\section{Dovepress}

patient perspectives such as quality of life, adherence and satisfaction. The manuscript management system is completely online and includes a very quick and fair peer-review system, which is all easy to use. Visit http://www.dovepress.com/testimonials.php to read real quotes from published authors. 